\title{
Role of Visco-Supplementation Following Micro- Fracture in Focal Chondral Lesions
}

\author{
Reetadyuti Mukhopadhyay* \\ Sports Injury Centre, VMMC \& Safdarjung Hospital, India
}

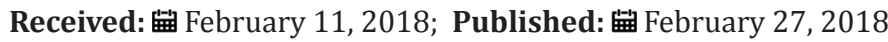

*Corresponding author: Reetadyuti Mukhopadhyay, Sports Injury Centre, VMMC \& Safdarjung Hospital, New Delhi, India.

\begin{abstract}
Introduction: Cartilage lesions pose a significant problem to surgeons, at best being replaced by poorer quality fibrocartilage post micro-fracture. Hyaluronic acid has shown to inhibit joint degeneration and reduce joint inflammation. This study wishes to evaluate the outcome of visco-supplementation following micro-fracture.
\end{abstract}

Material \& Method: Twenty one consecutive patients with chondral lesion less than $2 \mathrm{sq} \mathrm{cm}$ were treated with micro-fracture and post operatively randomly divide into two groups. One group was supplemented with intra-articular hyaluronic acid at 3 weeks post surgery. The patients were followed up at 3, 6 \& 12 months for WOMAC score and IKDC score.

Results: The WOMAC score and IKDC score in the visco-supplementation group were significantly better than those of the non visco-supplementation group at 6 months ( $\mathrm{p}=0.0001)$. At 12 months although the scores were significantly better than at 6 months, there was no significant difference between the two groups (WOMAC $\mathrm{p}=0.86$, IKDC $\mathrm{p}=0.347$ ).

Conclusion: Hyaluronic supplementations following micro-fracture ensure an early improvement in functional scores following micro-fracture. A longer follow up is necessary to evaluate its role in preventing further joint degeneration.

Keywords: Micro-fracture; Visco-supplementation; Hyaluronic acid

\section{Introduction}

Athletic injuries often lead to full-thickness chondral defects, which have limited intrinsic healing potential [1,2]. These lesions if not managed adequately predisposes to joint degeneration [2]. Symptomatic lesions are often managed with micro-fracture to attempt cartilage repair [3]. Bleeding from the sub-chondral bone within the defect and subsequent clot formation covers the exposed bone. Also, mesenchymal stem cells that migrate into the clot promote formation of fibrocartilagenous repair tissue [4]. This filling of the defect restores the congruity of the joint leading to symptomatic relief [5]. The viscoelastic property of the synovial fluid is credited to Hyaluronic acid, which is often used in the non operative treatment of early osteo-arthritis [6]. Hyaluronic acid has been shown to inhibit degenerative changes within chondrocytes, reduce synovial inflammation and enhance cartilage proteoglycan content along with inducing chondrogenic differentiation from mesenchymal cells $[7,8]$. This study aims to compare the functional outcome of micro-fracture with and without visco-supplementation.

\section{Materials and Method}

In a prospective level II study, patients with chondral lesions of ICRS grade III-IV measuring less than $2 \mathrm{sq} \mathrm{cm}$ were managed with micro-fracture and randomly divided into two groups. One group was supplemented with a single shot intra-articular Hyaluronic acid at 3 weeks post surgery in the form of $6 \mathrm{ml}$ hylan G-F 20, [9] the other group did not receive any visco-supplementation. Patients more than 45 years of age and having generalised chondral changes were excluded from the study. Multi-ligament injured patients and those with unmanaged single ligament injury or unmanaged meniscus injuries were also excluded from the study. There was no sex restriction. All the patients were put on continuous passive motion from the first post operative day unless they had under gone an associated PCL reconstruction or meniscus repair surgery, in which case PCL and meniscus rehabilitation protocols were followed. The patients were kept non weight bearing for 6 weeks 
followed by full weight bearing. WOMAC score and IKDC score were evaluated at 3, 6 and 12 months post surgery.

\section{Results}

The Visco-supplementation group (Group A) had 9 patients and the group with no supplementation (Group B) had 12 patients. All our patients were between 21-40 years of age (Mean: 29.3 years) with 14 males. Two had associated PCL reconstruction surgery, 17 underwent ACL reconstruction of which five underwent partial medial menisectomy and two partial lateral menisectomy. Five patients underwent a meniscus repair procedure. Eight of group A had grade 3-4 ICRS lesion on the weight bearing area of medial femoral condyle while one had involvement of the lateral femoral condyle. In group B 8 had involvement of the medial femoral condyle. Eight had injured their knee in a game of football, five while dancing, six while playing cricket and another two due to fall on stairs. None were lost to follow up. None of the patients reported any re-injury between the surgery and latest follow up. There were no complication in any of the patients and no one required any additional surgical intervention.

The WOMAC score in group A ranged from 54-49 (mean- 52) at 3 months, which improved to (mean-22.2) at 6 months. The WOMAC score at 12 months showed significant improvement from the 6 month follow up score $(\mathrm{p}=0.024)$, however there was no significant difference between group A and B at 12 months ( $p=0.86$ ). In group $B$ the WOMAC score at 6 months was better than that at 3 months $(\mathrm{P}=0.0001)$ (Table 1). But comparing with group A, group B showed significantly poorer results at 6 months $(\mathrm{p}=0.0001)$.

Table 1: WOMAC and IKDC scores of individual patients of group B at 3 months, 6 months and 12 months.

\begin{tabular}{|c|c|c|c|c|c|c|c|c|}
\hline \multicolumn{2}{|c|}{} & \multicolumn{3}{c|}{ WOMAC } & \multicolumn{3}{c|}{ IKDC } \\
\hline S.No. & Age & Sex & $\mathbf{3}$ Months & $\mathbf{6}$ Months & $\mathbf{1 2}$ Months & 3 Months & $\mathbf{6}$ Months & $\mathbf{1 2}$ Months \\
\hline 1 & 23 & M & 53 & 30 & 20 & 51.7 & 67.8 & 96.6 \\
\hline 2 & 25 & M & 50 & 34 & 19 & 52.9 & 69 & 3.1 \\
\hline 3 & 30 & M & 55 & 37 & 21 & 54 & 70.1 & 93.1 \\
\hline 4 & 31 & M & 54 & 35 & 20 & 52.9 & 66.7 & 94.3 \\
\hline 5 & 37 & F & 52 & 33 & 18 & 51.7 & 65.5 & 95.4 \\
\hline 6 & 26 & F & 53 & 32 & 17 & 49.4 & 64.4 & 94.3 \\
\hline 7 & 28 & F & 50 & 37 & 19 & 50.6 & 65.5 & 93.1 \\
\hline 8 & 36 & M & 56 & 35 & 22 & 49.4 & 64.4 & 93.1 \\
\hline 9 & 40 & M & 53 & 30 & 21 & 50.6 & 66.7 & 95.4 \\
\hline 10 & 22 & F & 57 & 32 & 20 & 52.9 & 69 & 95.4 \\
\hline 11 & 38 & M & 50 & 34 & 19 & 50.6 & 67.8 & 94.3 \\
\hline 12 & 21 & M & 49 & 31 & 23 & 49.4 & 70.1 & 93.1 \\
\hline
\end{tabular}

Comparing the IKDC scores, the group A patients showed significantly better results compared to group $B$ at 6 months follow up ( $\mathrm{p}=0.0001)$ (Table 2). The beneficial effect of visco- supplementation however seemed to wane away by 12 months with no significant difference in IKDC scores between the two groups ( $\mathrm{p}=0.347)$.

Table 2: WOMAC and IKDC scores of individual patients of group A at 3 months, 6 months and 12 months.

\begin{tabular}{|c|c|c|c|c|c|c|c|c|}
\hline & & & \multicolumn{3}{|c|}{ WOMAC } & \multicolumn{3}{|c|}{ IKDC } \\
\hline S.No. & Age & Sex & 3 Months & $\mathbf{6}$ Months & 12 Months & 3 Months & 6 Months & 12 Months \\
\hline 1 & 24 & M & 49 & 24 & 23 & 49.4 & 80.5 & 93.1 \\
\hline 2 & 27 & M & 54 & 20 & 20 & 52.9 & 79.3 & 94.3 \\
\hline 3 & 29 & F & 56 & 21 & 19 & 52.9 & 81.6 & 95.4 \\
\hline 4 & 30 & M & 53 & 25 & 18 & 51.7 & 82.8 & 93.1 \\
\hline 5 & 32 & M & 50 & 24 & 18 & 50.6 & 83.9 & 94.3 \\
\hline 6 & 35 & M & 49 & 23 & 19 & 49.4 & 81.6 & 94.3 \\
\hline 7 & 24 & M & 51 & 22 & 20 & 50.6 & 85.1 & 93.1 \\
\hline 8 & 37 & F & 52 & 20 & 20 & 52.9 & 86.2 & 95.4 \\
\hline 9 & 21 & F & 54 & 21 & 21 & 51.7 & 85.1 & 96.6 \\
\hline
\end{tabular}




\section{Discussion}

Joint degeneration and poor healing potential of chondral lesions pose a challenge to surgeons managing these lesions. Various techniques have been described aiming to fill the defect and obtain a congruent joint. Micro-fracture is one of such procedures in which the sub-chondral bone plate is penetrated to cause fibrin clot formation and later conversion to fibrocartilage [10]. Variable outcomes of micro-fracture have been described in literature with almost $70 \%-90 \%$ of patients showing improvement in function [11]. The durability of the fibrocartilage has however been put to question with mid-term results showing a decline in the functional scores $[12,13]$. Augmentation of micro-fracture to improve the quality and durability of the repair tissue and ensuring a more hyaline like tissue is the current interest topic of various researchers. Strauss E et al. [10] showed a positive effect of hyaluronic acid supplementation on repair tissue both histologically as well as grossly.

Intra-articular basic fibroblast growth factor when used without hyaluronic acid induces poor repair tissue besides undesirable side effects. hyaluronic acid injection along with basic fibroblast growth factor results in significantly better tissue quality [7]. Hyaluronic acid has been increasingly used in the non-operative management of osteoarthritis $[14,15]$. Rabbit model studies have demonstrated hyaluronic acid to reduce arthritic changes by inhibiting degenerative changes in chondrocytes and cartilage matrix. It also decreases synovial inflammation and increases proteoglycan contect of cartilage [7]. Hyaluronic acid has also been shown to induce chondrogenic differentiation in mesenchymal stem cells [8].

Tytherleigh-Strong et al. [6]. Demostrated significantly higher aggregate moduli in the visco-supplementation group in an ovine model. Jansen et al showed chondroprotective effect of hyaluronic acid, preventing apoptosis of chondrocytes just adjacent to the lesion [16]. Although there are several animal studies demonstrating beneficial effect of hyaluronic acid in cartilage healing, not much is available on their role in human patients [10].

This study aimed to evaluate the role of visco-supplementation in functional outcome following micro-fracture in focal chondral lesions. The visco-supplemented group fared significantly better than the non-supplemented group at 6 months. The beneficial effect however seemed to wane away by one year with both groups having comparable functional scores and subjective outcomes at 12 months follow up.

\section{Limitations}

Our sample size is small as we purposefully selected only lesions which were less than $2 \mathrm{sq} \mathrm{cm}$ in size. Credibility is added to our study by comparing the outcomes of micro-fracture supplemented with hyaluronic acid with those without. No patients were lost to follow up in this series. We however, do not have any follow up MRI or repeat arthroscopy to ascertain the healing status at the repair site. The follow up is also a short term follow up 1 year. A longer term follow up is needed to assess the long term outcomes of viscosupplementation in preventing joint degeneration.

\section{Conclusion}

Supplementing micro-fracture with hyaluronic acid injection ensures quicker return of better functional state. In the longer term however this beneficial effect seems to wane off.

\section{References}

1. Buckwalter JA (2002) Articular cartilage injuries. Clin Orthop Relat Res 402: 21-37.

2. Mankin HJ (1982) The response of articular cartilage to mechanical injury. J Bone Joint Surg Am 64(3): 460-466.

3. Mithoefer K, Williams RJ $3^{\text {rd, }}$ Warren RF, Potter HG, Spock CR, et al. (2005) The microfracture technique for the treatment of articular cartilage lesions in the knee: a prospective cohort study. J Bone Joint Surg Am 87(9): 1911-1920.

4. Shapiro F, Koide S, Glimcher MJ (1993) Cell origin and differentiation in the repair of full-thickness defects of articular cartilage. J Bone Joint Surg Am 75(4): 532-553.

5. Frisbie DD, Trotter GW, Powers BE, Rodkey WG, Steadman JR, et al. (1999) Arthroscopic subchondral bone plate microfracture technique augments healing of large chondral defects in the radial carpal bone and medial femoral condyle of horses. Vet Surg 28(4): 242-255.

6. Tytherleigh-Strong G, Hurtig M, Miniaci A (2005) Intra-articular hyaluronan following autogenous osteochondral grafting of the knee. Arthroscopy 21(8): 999-1005.

7. Miyakoshi N, Kobayashi M, Nozaka K, Okada K, Shimada Y, Itoi E (2005) Effects of intraarticular administration of basic fibroblast growth factor with hyaluronic acid on osteochondral defects of the knee in rabbits. Arch Orthop Trauma Surg 125(10): 683-692.

8. Kujawa MJ, Caplan AI (1986) Hyaluronic acid bonded to cell-culture surfaces stimulates chondrogenesis in stage 24 limb mesenchyme cell cultures. Dev Biol 114(2): 504-518.

9. Chevalier X, Jerosch J, Goupille P, van Dijk N, Luyten FP, et al. (2010) Single, intra-articular treatment with 6 ml hylan G-F 20 in patients with symptomatic primary osteoarthritis of the knee: a randomised, multicentre, double-blind, placebo controlled trial. Ann of the Rheum Dis 69(1): 113-119.

10. Strauss E, Schachter A, Frenkel S, Rosen J (2009) The Efficacy of IntraArticular Hyaluronan Injection After the Microfracture Technique for the Treatment of Articular Cartilage Lesions. Am J Sports Med 37(4): 720-726.

11. Williams RJ $3^{\text {rd }}$, Harnly HW (2007) Microfracture: indications, technique, and results. Instr Course Lect 56: 419-428.

12. Gobbi A, Nunag P, Malinowski K (2005) Treatment of full thickness chondral lesions of the knee with microfracture in a group of athletes. Knee Surg Sports Traumatol Arthrosc 13(3): 213-221.

13. Steadman JR, Briggs KK, Rodrigo JJ, Kocher MS, Gill TJ, et al. (2003) Outcomes of microfracture for traumatic chondral defects of the knee: average 11-year follow-up. Arthroscopy 19(5):477-484.

14. Altman RD (2000) Intra-articular sodium hyaluronate in osteoarthritis of the knee. Semin Arthritis Rheum 30(2 Suppl 1): 11-18. 
15. Wobig M, Dickhut A, Maier R, Vetter G (1998) Viscosupplementation with hylan G-F 20: a 26-week controlled trial of efficacy and safety in the osteoarthritic knee. Clin Ther 20(3): 410-423.
16. Jansen EJ, Emans PJ, Douw CM, Douw CM, Guldemond NA, et al. (2008) One intra-articular injection of hyaluronan prevents cell death and improves cell metabolism in a model of injured articular cartilage in the rabbit. J Orthop Res 26(5): 624-630.

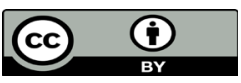

This work is licensed under Creative Commons Attribution 4.0 License

To Submit Your Article Click Here:

Submit Article

DOI: 10.32474/OSMOAJ.2018.01.000102

$\begin{gathered}\text { Orthopedics and Sports Medicine } \\ \text { Open Access Journal }\end{gathered}$
Assets of Publishing with us
- Global archiving of articles
- Immediate, unrestricted online access
- Rigorous Peer Review Process
- Authors Retain Copyrights
- Unique DOI for all articles

